\title{
EQUILIBRIUM EFFECTS OF PUBLIC GOODS: THE IMPACT OF COMMUNITY WATER FLUORIDATION ON DENTISTS
}

\author{
Katherine Ho \\ Matthew Neidell \\ Working Paper 15056 \\ http://www.nber.org/papers/w15056
}
NATIONAL BUREAU OF ECONOMIC RESEARCH
1050 Massachusetts Avenue
Cambridge, MA 02138
June 2009

We would like to thank Leemore Dafny, Sherry Glied, Bhaven Sampat, and Josh Graff Zivin for many helpful suggestions and Aaron Szott for excellent research assistance. The views expressed herein are those of the author(s) and do not necessarily reflect the views of the National Bureau of Economic Research.

NBER working papers are circulated for discussion and comment purposes. They have not been peerreviewed or been subject to the review by the NBER Board of Directors that accompanies official NBER publications.

(C) 2009 by Katherine Ho and Matthew Neidell. All rights reserved. Short sections of text, not to exceed two paragraphs, may be quoted without explicit permission provided that full credit, including $\odot$ notice, is given to the source. 
Equilibrium effects of public goods: The impact of community water fluoridation on dentists Katherine Ho and Matthew Neidell

NBER Working Paper No. 15056

June 2009

JEL No. H41,H51,I11,J24,L22

\begin{abstract}
$\underline{\text { ABSTRACT }}$
In this paper we consider how the dental industry responded to the addition of fluoride to public drinking water. We take advantage of the staggered introduction of fluoridation throughout the country to analyze the changes in numbers of within-county dentists relative to physicians in the years surrounding the change in fluoridation status. We find a significant decrease in the number of dental establishments and an even larger reduction in the number of employees per firm following fluoridation. We also find that fluoridation in neighboring markets was associated with an increase in own-market dental supply, suggesting that dentists responded to the demand shock by moving from fluoridated areas to close-by markets. Further analysis suggests that some dentists may have retrained as specialists rather than moving geographically. Our estimates imply that the 8 percentage point change in exposure to water fluoridation from 1974 to 1992 may have led to the loss of as many as 0.6 percent of dental establishments and 2.1 percent of dental employees, suggesting a substantial net impact of this public good on the dental profession since its inception.
\end{abstract}

Katherine Ho

Columbia University

Department of Economics

1037 International Affairs Building

420 West 118th Street

New York, NY 10027

and NBER

kh2214@columbia.edu

Matthew Neidell

Department of Health Policy and Management

Columbia University

600 W 168th Street, 6th Floor

New York, NY 10032

and NBER

mn2191@columbia.edu 


\section{Introduction}

Shortly after researchers found that communities with higher rates of naturally occurring fluoride had lower rates of tooth decay (Dean, 1938), public water systems began adding fluoride to public drinking water. ${ }^{1}$ As a result, the incidence of tooth decay fell dramatically in fluoridated communities (Burt and Eklund, 1999) ${ }^{2}$, leading to a period of widespread adoption of community water fluoridation. By 2006, nearly 70\% of the U.S. population served by public water systems received fluoridated water (CDC, 2008). Given the significant reduction in tooth decay, extremely low incidence of side-effects, and low costs to provide ${ }^{3}$, community water fluoridation (CWF) has been called "one of the 10 greatest public health achievements of the 20th century” (CDC, 1999).

Fluoridation can be viewed as a public good that substitutes for a private good: once added to the water supply, all consumers in the area are provided with a perfect substitute for privately available dietary fluoride supplements. ${ }^{4}$ The equilibrium impacts of this public good, however, likely extend far beyond the market for fluoride. Prior to the availability of dietary fluoride, formal dental care was the primary method for treating tooth decay. Since CWF lowers the incidence of tooth decay, it serves as a partial substitute for dental care. By lowering the demand for formal dental care, CWF may also impact the number of practicing dentists. ${ }^{5}$ Furthermore, since the dental profession offers a wide range of services in addition to treating tooth decay, dentists may respond to this reduced demand by shifting into other closely related

\footnotetext{
1 The first community to add fluoride to drinking water was Grand Rapids, MI in 1945,

${ }^{2}$ However, some sources dispute this. See Section 5 for a discussion.

${ }^{3}$ The estimated costs of fluoridation per person per year are $\$ 0.50$ for communities with greater than 20,000 people, $\$ 1$ for communities with $10-20,00$ people, $\$ 1.50$ for communities with 5-10,000 people, and \$3 if fewer than 5,000 people (Griffin et al., 2001)

${ }^{4}$ CWF may be not a public good if a water shortage makes it rivalrous, but this is extremely uncommon in our sample.

${ }^{5}$ Interestingly, despite the potential consequences on the industry, dentists generally support community water fluoridation (http://www.ada.org/public/topics/fluoride/index.asp)
} 
occupations within the industry not impacted by CWF, such as orthodontics or cosmetics. The high reported success and widespread adoption of water fluoridation suggests the technological impact from this simple public good may have dramatically transformed the dental industry.

In this paper we use several administrative files at the county-level to explore how the dental industry changed in response to the provision of fluoridated water in the 1970s - 1990s. We take advantage of the staggered introduction of fluoridation throughout the country to compare the changes in numbers of within-county dentists in the years surrounding the change in fluoridation status. Since decisions regarding water fluoridation may be endogeneous, we include data on physicians - a comparably skilled group affected by local public health policies but unaffected by water fluoridation - as a control group to estimate difference in differences models. ${ }^{6}$ We assume that changes in fluoridation status are exogenous to other factors that may have affected dental supply differentially from physician supply. The adoption of water fluoridation can therefore be used to identify the causal affect of fluoridation on the number of dentists.

We find substantial evidence of a response. First, using data from the County Business Patterns, we uncover a statistically significant decrease in the number of dental establishments, but an even more substantial decrease in the number of dental employees and payroll. A move from 0 to $100 \%$ fluoridation is associated with a $9 \%$ reduction in the number of establishments compared to a nearly $25 \%$ reduction in the average number of employees per firm. Second, we find that fluoridation in neighboring markets increases own-market dental supply, supporting the hypothesis that dentists moved from fluoridated areas to close-by markets that had not yet been affected by this negative demand shock. Several robustness checks support the validity of these

\footnotetext{
${ }^{6}$ This control group is invalid if dentists switched to being a physician in response to CWF. Of the 322 dentists and 1359 physicians identified in the Panel Study of Income Dynamics and followed for roughly the same time period, none switched between the two professions, suggesting this is an unlikely response.
} 
findings. Our estimates imply that the 8 percentage point change in exposure to water fluoridation from 1974 to 1992 may have led to the loss of as many as 0.6 percent of dental establishments and 2.1 percent of dental employees. Given current fluoridation rates of 70 percent, this suggests that community water fluoridation has had a substantial overall impact on the dental profession.

Although our main results indicate that some dentists changed geographic location by moving to a neighboring market, the effect on neighbors is smaller in magnitude than the owncounty effect, suggesting that some dentists responded to fluoridation by leaving the profession or retraining as specialists. We probe this using data from the Area Resource File, which contains details on the composition of dentists. We find that the proportion of general practitioners - dentists most affected by fluoridation - declined relative to specialists after fluoridation, supporting the idea that general practitioners were more likely to leave the market or retrain in dental specialties where demand did not fall. Although not statistically significant, we also find that the exit was concentrated among younger dentists, a notion consistent with retraining in response to technological change since younger workers have a longer time horizon to reap its benefits (Bartel and Sicherman, 1993). While not definitive, this evidence supports the hypothesis that the widespread adoption of water fluoridation is partially responsible for the recent growth in dental specialties: the significant reduction in tooth decay led to a fundamental shift in the demand for dentists, which forced dentists to retrain in other areas of dentistry where sufficient demand exists. ${ }^{7}$

In addition to understanding the equilibrium effects of a public good, we also relate our findings to two additional areas. First, these results relate to the literature on industry structure

\footnotetext{
${ }^{7}$ This finding also potentially relates to supplier-induced demand: the retraining of out of work dentists increased the supply of specialists, which may have increased the demand for specialty services beyond what patients may have demanded themselves.
} 
dynamics. Numerous papers have investigated the flows of employment across firms and sectors over time, comparing the changes in the average size and number of firms in response to demand or cost shocks. Most of the literature relates to the manufacturing industry, where substantial evidence indicates that changes at surviving producers (such as plant expansions and contractions) dominate changes in the number of plants or firms. ${ }^{8}$ In contrast, evidence on the retail industry finds that the number of stores generally responds more than the average size of each store (Campbell and Lapham, 2004). Our results shed some light on dynamics in the service industry, a sector that has experienced considerable change in recent years but has not been considered in detail by this literature. We find that dentists behave similarly to manufacturers, rather than retailers, in their response to aggregate shifts in demand. These results will assist in evaluating policies that attempt to either move employment from declining to growing industries or encourage new firm creation.

Second, our results provide evidence that dentists respond to economic incentives. Numerous models of firm entry and exit in the industrial organization literature predict that firms should enter markets that, all else equal, have small numbers of competitors and high demand for their services, and exit markets where the opposite is true. ${ }^{9}$ Whether these predictions hold true in health care markets is unclear both because of inefficiencies, such as those caused by moral hazard, adverse selection, insurance distortions, and physician-induced demand, and because employees in health fields may maximize something other than a simple profit function (Lakdawala and Philipson, 1998; Newhouse, 1970). A number of previous papers generally find

\footnotetext{
${ }^{8}$ See Dunne, Roberts and Samuelson (1989a, 1989b) and Armington and Odle (1982) for evidence of job creation and destruction for U.S. manufacturers. Other relevant papers in this literature include Campbell and Hubbard (2008) which considers the impact of the construction of the Interstate Highway System in the U.S. on the supply of highway service stations. Theoretical papers such as Hopenhayn (1992) and Fishman and Rob (2003) develop models of firm size, entry and exit that are motivated by observations of frequent entry and exit in many U.S. industries.

${ }^{9}$ See Berry and Reiss (2007) for a survey of this literature.
} 
evidence of rational responses to incentives, but typically focus on the intensive margin, such as responses to changes in prices (Cutler, 1990, 1995; Dafny, 2005) and contracts (Rebitzer and Taylor, 2004). Our paper instead considers the extensive margin, analyzing dentists’ responses to changes in demand in terms of market entry and exit. This addresses mounting policy concerns regarding shortages in supply of health care professionals that are expected to worsen as baby boomers continue to age and place an increased demand on the health care system (Buerhaus, Staiger, and Auerbach, 2009; Iglehart, 2008).

\section{Data}

\section{2.a. Data on $\mathrm{CWF}$}

The 1992 Water Fluoridation Census compiled by the CDC contains detailed information on the fluoridation status of every public water system in the United States. Each state provided information to the CDC for each water system within the state, including the date fluoridation began, whether the fluoride was naturally occurring or chemically adjusted, the county served, and the population served by the water system within the county as of $1990{ }^{10}$

To derive a panel of fluoridation rates at the county level, we first compute the percent of each county in the U.S. with access to fluoridated water. To do this, we merge the Fluoridation Census data with total population estimates of each county from the 1990 Census of Population and Housing to compute the percent of the county with fluoridated water in 1990. To determine county fluoridation rates for prior years, absent any alternative data source we must assume the percent of the population served by each water system is constant over time. Using the date fluoridation began, we then assign this same percent fluoridated to the county for all years after fluoridation began and zero to all years prior to fluoridation. If there are multiple fluoridating

\footnotetext{
${ }^{10}$ If the water system served multiple counties, information for each county served was separately recorded. Multiple water systems within a county were also separately reported.
} 
water districts within a county, as is often the case, we average the percent fluoridated using the population served by each district as weights. This leaves us with a county-year panel of fluoridation rates.

To clarify this measure, consider a county with only one water district that fluoridates, which began doing so in 1980 . As of 1990 , this water district served 1000 people within the county and the total population of the county was 5000, suggesting a fluoridation rate of 0.2 $(=1000 / 5000)$ in 1990. We assign a fluoridation rate of 0.2 to all years from $1980-1990$ and assign a fluoridation rate of 0 for years prior to 1980 .

\section{2.b. County Business Patterns}

We measure the supply of dentists in each county over time using data from the county business patterns (CBP), maintained by the U.S. Census Bureau. It is an annual series that contains counts of the total number of establishments and total number of employees (as of midMarch) as well as first-quarter total payroll for each industry at the county level. ${ }^{11}$ Variables are derived from the Economic Censuses, Annual Survey of Manufacturers, and Internal Revenue Service. The industry is identified using the Standard Industrial Classification (SIC), which provides separate categories for "offices and clinics of dentists" (802) and "offices and clinics of medical doctors” (801). We use the latter as control group. These categories include all individuals employed within the establishment, so "offices and clinics of dentists" includes dentists, hygienists, and receptionists. While there is no missing data on establishment numbers, the total number of employees and payroll are missing for roughly 30 percent of observations. Whenever this arises, however, a categorical breakdown of the number of employees is available. For example, in a county where we know how many establishments there are but not

\footnotetext{
${ }^{11}$ We adjust payroll data by the consumer price index.
} 
the number of employees, we do know how many establishments have 1-4 employees. ${ }^{12}$ We use these categories along with three lags and leads of employment to impute missing values to preserve sample size. We do not impute payroll since there are no categorical counterparts. We use data from the years 1974-1992 since CBP data prior to 1974 are often missing and 1992 is the last year for which we have fluoridation rates.

\section{2.c. Other Data Sources}

We use the Bureau of Health Professions Area Resource File (ARF), maintained by the Health Resources and Services Administration within the United States Department of Health and Human Services, as a source of data on changes within the dental industry. The ARF is a county-based data file summarizing secondary data from a wide variety of sources. In focusing on dentists, we use variables summarized from the American Dental Association "Distribution of Dentists in the U.S.” report, which is census of all dentists in the U.S., available in 1981 and 1987 at the county level. Relevant variables for our analysis include the total number of practicing dentists, the number of dentists in general practice and pediatric dentistry versus a specialty, the number of dentists practicing full- versus part-time, the age distribution of dentists (in five year intervals), and the number of dentists employed in public agencies or private practice.

We add a number of county level variables to our regressions to account for other changes over time that may be correlated with fluoridation status and affect the number of dentists. To account for potential shifts in dental supply because of changes in local labor market composition, we use the County Business Patterns data on the percent of workforce

\footnotetext{
${ }^{12}$ The categorical breakdown report the number of employees in each of the following categories: 1-4, 5-9, 10-19, 20-49, 50-99, 100-249, 250-499, 500-999, and 1000+. 94.6\% had less than 10 employees and 99.5\% had less than 20.
} 
employed in each of the major SIC categories. ${ }^{13}$ To account for possible changes in the demand for dental services due to income shocks or changes in local public expenditures that may be correlated with CWF changes, we also include county level data from the 1974-1992 Bureau of Economic Analysis (BEA) Regional Economic Information System. Finally we account for possible shifts in the demand for dental care due to population changes by including population data taken from the U.S. Census Bureau. ${ }^{14}$

In addition to the county-year panel, we also utilize cross-sectional data from the CDC's Behavioral Risk Factor Surveillance System (BRFSS) for 1999, the first year when all relevant data were collected. This is used in a separate analysis to investigate the relationship between community water fluoridation and the frequency of preventative dental visits; see below for details. The BRFSS is an annual survey designed to elicit prevalence of major behavioral risks among adults. It contains data on the last time each individual had their teeth cleaned by a dentist or dental hygienist, with the following categorical responses: within the past year (72.8 percent of respondents), 1 to 2 years ago (11.8 percent), 2 to 5 years ago ( 7.5 percent), and 5 or more years ago (8.0 percent). It also includes county of residence, which we use to merge with CWF data and with data from the 2000 City and County Data Books to account for possible confounding factors, including population density, median age, percent race/ethnicity breakdown, persons per household, death rate, infant mortality rate, percent HS grads, percents college grades, median HH income, percent poverty, unemployment rate, and the social security collection rate.

\section{2.d. Summary statistics}

\footnotetext{
${ }^{13}$ The SIC categories are agriculture (first two digits of SIC $=7$ ); mineral industries $($ SIC $=10)$; construction (SIC = 15); manufacturing (SIC = 20); transportation, communication, and utilities ( $\mathrm{SIC}=40$ ); wholesale trade (SIC = 50); retail trade (SIC $=52$ ); finance, insurance, and real estate (SIC $=60$ ); and service industries (SIC $=70$ ).

${ }^{14}$ For more information on county population estimates, see http://www.census.gov/popest/topics/methodology/2006_st_char_meth.html.
} 
Table 1 shows time trends in our key variables for counties included in the final sample used in our analysis. Our final sample covers over 96 percent of all US counties and over 97 percent of the US population, with less than 100 percent coverage largely due to missing data from the fluoridation census for Arkansas, which contains 2 percent of all counties and 1 percent of the population. Several features are worth highlighting. One, the number of dental establishments did not increase considerably over time, with roughly one establishment per 3,900 people in 1974 and one per 3,100 in 1992. The number of employees, however, nearly doubled over time from 1 employee per 1,250 people in 1974 to 1 per 570 in 1992, and payroll tripled (inflation adjusted). This suggests that while this industry has grown over time, it has also experienced important changes in market structure over time. Third, growth rates of physicians followed comparable patterns to dentists, suggesting the plausibility of using physicians as a control group. Finally, the change in fluoridation rates over time is fairly small, going from $45 \%$ of the population with access to CWF in 1974 to 53\% in 1992 (current rates are around 67\%). However, we shall see that this had a substantial effect on the number of dentists.

\section{Econometric model}

\section{3.a. Main model}

To infer the impact of CWF, we use a difference in difference strategy that compares how the number of dentists responds to changes in the fluoridation rate relative to physicians within counties over time. We account for the possibility that counties that fluoridated earlier or to differing degrees differed from those that fluoridated later, for example, due to concurrent expansions in other public health programs, by using physicians as a control group. ${ }^{15}$ We reason that these expansions are likely to affect the supply of all health professionals, including

\footnotetext{
${ }^{15}$ Note that this differs from the assumption of Glied and Neidell (2009), who argue fluoridation decisions were exogenous. This difference is due to our focus on a later time period (they focused on 1957-64) and different outcome (they focused on earnings).
} 
physicians as well as dentists. Our key assumption is that, absent CWF, the trends in physician and dentist supply would have been identical. Importantly, however, the demand for physicians is not affected by water fluoridation.

We estimate the following econometric model:

(1) $Y_{c t d}=\beta_{1} * \operatorname{dent}_{d}+\beta_{2}{ }^{*} C W F_{c t}+\beta_{3}{ }^{*} \operatorname{dent}_{d} * C W F_{c t}+\delta_{I} * X_{i t}+\delta_{1} * \operatorname{dent}_{d} * X_{i t}+\eta_{t}+\operatorname{dent}_{d} * \eta_{t}+\alpha_{c}+$ $\varepsilon_{c t}$

where the subscript $c$ is the county, $t$ is the year, and $d$ is the profession (dentist or physician). $Y$ is a measure of supply, described in more detail below. The variable $d e n t_{d}$ is an indicator for whether $Y$ corresponds to dentists or physicians. $C W F_{c t}$ is the contemporaneous measure of water fluoridation in the county, which ranges from 0 to $1 . \operatorname{dent}_{d} * C W F_{c t}$ is the key parameter of interest: it measures the differential impact of CWF on dentists relative to physicians. $X_{i t}$ are a large set of time-varying county level covariates that may affect dentists or physicians, and $\operatorname{dent}_{d} * X_{i t}$ allows these covariates to have a differential impact on dentists. ${ }^{16} \eta_{t}$ is a year fixed effect to absorb annual trends common across all counties, and is also interacted with dent $_{d}$ to allow for separate annual trends for dentists. $\alpha_{c}$ is a county fixed effect to absorb all timeinvariant characteristics of the county.

We begin by examining the net impact of CWF on supply and payroll, defining the dependent variables as the number of establishments, number of employees, and quarterly payroll (in \$1 million), with all three reported in per 1000 capita. To explore industry dynamics,

\footnotetext{
${ }^{16}$ The covariates included in $X_{i t}$ are the percent of workforce employed in each of the major SIC categories, the total population and the percent of population within each of five age categories (0-19, 20-39, 40-59, 60-79, and 80 and over), Medicare payments, Medicaid payments, military medical insurance payments, supplemental security income payments, Aid to Families with Dependent Children payments, food stamps payments, unemployment insurance compensation, veterans benefits, federal education and training assistance, current transfer receipts of nonprofit institutions, current transfer receipts of individuals from businesses, average earnings per job , per capita income, and employment to population ratio.
} 
we also examine the impact of CWF on employees per establishment, payroll per establishment, and payroll per employee.

\section{3.b. Accounting for neighboring CWF}

As previously mentioned, the industrial organization literature on firm entry and exit leads us to expect neighboring counties' CWF to have a positive impact on own-county dentist supply. We therefore also extend this model by including neighboring county fluoridation status.

(2) $Y_{c c^{\prime} t d}=\beta_{1} * \operatorname{dent}_{d}+\beta_{2} * C W F_{c t}+\beta_{3} * \operatorname{dent}_{d} * C W F_{c t}+\beta_{4} * C W F_{c^{\prime} t}+\beta_{5} * \operatorname{dent}^{*} C W F_{c^{\prime} t}$

$+\delta_{1} * X_{i t}+\delta_{1} * \operatorname{dent}_{d} * X_{i t}+\eta_{t}+\operatorname{dent}_{d} * \eta_{t}+\alpha_{c}+\varepsilon_{c t}$

where $c^{\prime}$ is the neighboring county.

Rather than limit neighboring counties to those that share a border, we define a neighboring county as one whose population weighted centroid is within a certain distance from the population weighted centroid of the reference county. This allows for a more realistic setting whereby dentists care about the physical distance between possible locations rather than whether they share a political border. Such a distinction may arise in urban areas where counties have small land areas, and much of our analysis focus on urban areas because of the returns to scale in providing CWF. For this analysis we focus on counties that have a neighboring county within 40 miles, though results are generally insensitive to this choice.

Since each county varies in the number of neighbors, we use two different measures of neighbor fluoridation status: first we use CWF of closest neighbor and second we separately include the CWF of all neighbors. ${ }^{17}$ We estimate these models using the same dependent variables as in section 3.a.

\section{3.c. Changes within the industry}

\footnotetext{
${ }^{17}$ Note that including data on all neighbors increases our sample size by the average number of neighboring counties, so we cluster by the reference county to account for this larger sample size. We also estimated models using the average CWF of neighbors and found very similar results.
} 
To further explore changes within the dental industry, we use the ARF data on dentists by specialty. We estimate a variant of equation (1), focusing on dentists only:

(3) $Y_{c t}=\beta^{*} C W F_{c t}+\delta^{*} X_{i t}+\eta_{t}+\alpha_{c}+\alpha_{c}{ }^{*} t+\varepsilon_{c t}$

We include only dentists in this equation, rather than considering their response compared to physicians, for two reasons. First we wish to explore changes in the composition of the dentist category, rather than analyzing changes in levels. Second, the variables we consider do not have identical meanings for physicians.

We specify the dependent variable as the rate of dentists who are: 1) in general practice or pediatric dentistry; 2) full-time; 3) age $<44$; and 4) in private practice. Our rationale for focusing on these four outcomes is the following. Since tooth decay is a topic of concern to general practitioners, CWF should reduce the number of dentists in general practice relative to those in specialty areas, either by shifting general practitioners into specialties or by moving them out of the profession entirely. Some of the losses in employment in the dental industry may be observed as shifts from full-time to part-time employment rather than as market exit. Younger dentists may be more willing to leave the market and retrain themselves since they have a longer time horizon to earn profits from entering a new market. For these three outcomes, we expect to estimate a negative coefficient on CWF. Last, we focus on dentists in private practice as a specification check for our model. If areas that fluoridated also increased spending on additional programs to improve oral health, this could have decreased the demand for dentists relative to physicians and therefore confounded our identification strategy. In that case we might expect to see an increase in the number of dentists practicing at public agencies (which were 
bolstered by the local areas' increased spending). We therefore hope for a negative or insignificant coefficient in this regression. ${ }^{18}$

\section{Results}

Table 2 presents our main results. We find strong evidence of a decrease in dental supply in response to the adoption of community water fluoridation. Column (1) shows that adopting CWF is associated with a statistically significant decrease of .026 dental establishments per 1000 people. Given the baseline of roughly 0.3 establishments per 1000 people, this implies a $9 \%$ reduction for a change from 0 to $100 \%$ of the population with access to fluoridated water, or a 0.7 percent reduction for the 8 percentage point change in fluoridation we observe in our sample. Column (2) shows a statistically significant drop of 0.5 employees per 1000 people, which corresponds to a 37 percent decrease going from 0 to $100 \%$ fluoridation or 3 percent decrease for the 8 percentage point change in fluoridation rates in our sample. This suggests a much higher impact on employees per establishment than on establishments ${ }^{19}$. The impact of CWF on quarterly payroll is also statistically significant, though the impact of a less than 1 percent decrease is much smaller than the loss in employment. Overall, these results suggest statistically significant declines in the supply of dentists.

In the second panel of Table 2 we explore the robustness of our results by allowing for county specific linear time trends. ${ }^{20}$ If areas that fluoridate experience other trends specific to that county this may bias our baseline results and lead this robustness test to have different results from the main analysis. However, we find that adding these county time trends has virtually no impact on our results.

\footnotetext{
${ }^{18}$ Since our dependent variable is a rate, we weight these regressions by the numerator since counties with a larger number of dentists provide more precise estimates of the rate.

${ }^{19}$ There are approximately 4.5 employees per establishment.

This amounts to adding $\alpha_{c}{ }^{*} t$ to equation 1.
} 
In Table 3 we explore the impacts of CWF on industry dynamics in more detail by examining rate of employees per establishment. Consistent with a larger impact on employees, we find a statistically significant, negative coefficient on CWF using employees per establishment as the dependent variable. The coefficient of -1.23 suggests a nearly 25 percent decline in the size of remaining establishments. We also find statistically significant decreases in payroll per establishment or employee, suggesting that in addition to firms and employees leaving average wage rates fell.

In Table 4, we include information on neighboring counties' fluoridation status. As expected we find that fluoridation in neighboring counties has a positive effect on own-county dental supply, suggesting dentists relocate to nearby markets where fluoridation rates are lower. These estimates are insensitive to whether we measure neighbor CWF using all neighbors within 40 miles (panel A) or the physically closest neighbor (panel B). The results from this Table also provide two additional robustness checks of our model. First, the coefficients on own CWF remains largely unchanged, suggesting that spatial patterns in CWF rates are not an important confounder in our analysis. Second, the coefficient on neighboring county CWF is smaller than the coefficient on own, as we would expect given that dentists can relocate to other counties or leave the industry entirely. These findings lend support to the validity of our model.

In Table 5, we present results that further probe changes within the industry by examining the composition of dentists using data from the ARF. In column (1), we find a statistically significant decrease in the proportion of dentists who are general practitioners. This supports the hypothesis that, since general practitioners are more likely than specialists to see a decrease in demand because of fluoridation, they are more likely to exit the market. Although not statistically significant, column (2) shows a decrease in the proportion of full-time 
employees, evidence consistent with a shift towards more part-time employment. We also see a decrease in the proportion of dentists who are aged under 44, consistent with younger workers having more time to earn from their retraining, but this too is not statistically significant. Lastly, we find that CWF does not have a statistically significant association with the rate of dentists employed in private practice, with a t-statistic less than 0.2 . This specification check provides some reassurance that local governments that fluoridated did not provide additional investments that might have decreased demand for (and thus supply of) of dentists during our panel by increasing the number of dentists at public agencies.

\section{4.b. Compensatory behavior}

We conduct one further analysis to investigate possible welfare effects of CWF. While the supply response to water fluoridation suggests that fluoride exposure leads to improved dental health, there is one potential caveat to this interpretation of our results. If, as our results indicate, dentists responded to the reduction in demand for their services by moving away from the area, consumers may have found it more difficult to access dental care. As a result, some aspects of dental health not impacted by fluoride, particularly periodontal health, may have suffered.

We test this hypothesis using the BRFSS data. We reason that, if the above story is correct, we should observe a negative relationship between water fluoridation and periodontal care. In fact we find, if anything, the opposite correlation. We estimate models using two different dependent variables. First, we estimate a linear probability model for whether an individual had a cleaning in the past year, focusing on this category because the American Dental Association recommends dental cleanings twice a year. Second, we estimate an interval regression model to exploit the full range of categorical responses; we interpret this estimate as 
the amount of time between dental cleanings. We include several demographic variables to account for individuals’ socio-economic status and ability to afford care: race, education, marital status, number of children, employment status and health insurance status. To account for an individual's initial health status and propensity to consume preventative care, we include body mass index, diabetes status, mental health status, smoking status, and having blood pressure tests and routine physician checkups. We also include the county level variables from the 2000 City and County Data Books listed in Section 2e.

As shown in Table 6, fluoridation status is associated with a statistically insignificant 1 percentage point increase in having a dental cleaning within the past year, from a baseline rate of $72 \%$. The results of interval regressions indicate that fluoridation status is associated with having a cleaning approximately 12 days sooner than if not fluoridated, though it is also statistically insignificant. The results are insensitive to sequentially adding the demographic and health behavior variables. Given that our results are already insensitive to numerous controls, it is difficult to believe that including more confounding variables would make the coefficients switch sign. This evidence therefore indicates that consumer demand for dental services, at least on average, probably did not fall by more than the amount justified by water fluoridation.

\section{Discussion and Conclusion}

Although fluoridation of community drinking water is a relatively simple government program, in this paper we demonstrate substantial effects from this public good on the dental industry. After the introduction of fluoridation to a local community, the number of dental establishments and employees per establishment both fell significantly, with the latter falling faster than the former. We also find that the number of own-county dentists increased with neighboring fluoridation rates and that general practice dentists were more likely to leave the 
profession compared to specialists. The most likely interpretation of our results is that the public provision of fluoridated water was effective in reducing demand for private substitutes, such as dental services, and that supply responded to this negative demand shock. Our estimates suggest the advent of water fluoridation significantly transformed the dental industry.

Despite widespread support for water fluoridation by leading medical and public health authorities, controversy surrounds water fluoridation, with disputes often centering on the apparent benefits to oral health. The seminal fluoridation experiments conducted in NewburghKingston, NY, Grand Rapids-Muskegon, MI, Evanston-Oak Park, IL, and Brantford-Sarnia, Ontario, Canada in the 1940s and 50s found fluoridation dramatically lowered the incidence of dental caries by roughly 50-70 percent (Burt and Eklund, 1999), but more recent evidence suggests the impact may be much smaller (Brunelle and Carlos, 1990; Newbrun, 1989) or nonexistent (Diesendorf, 1986; Yiamouyiannis, 1990). Without benefits from fluoride exposure, however, dentists would have had little reason to move away from fluoridated areas towards those not yet fluoridated. ${ }^{21}$ The reduction in the number of dentists is therefore likely to have been a response to actual changes in demand, suggesting community water fluoridation led to a significant improvement in oral health. These improvements in oral health combined with reduced expenditures on dental services no longer necessary suggests community water fluoridation likely had a large, positive effect on social welfare.

\footnotetext{
${ }^{21}$ This is particularly clear given that consumers were often uninformed about whether fluoride had been added to their water supply; disclosure of fluoride content was not made mandatory until the 1996 amendment to the Safe Drinking Water Act.
} 


\section{References}

1) Armington C. and Odle M. 1982. "Small Business - How Many Jobs?” Brookings Review 1: 14-17.

2) Bartel A.P. and Sicherman N. 1993. “Technological Change and Retirement Decisions of Older Workers”. Journal of Labor Economics 11(1): 162-183.

3) Berry S. and P. Reiss. 2007. "Empirical Models of Entry and Market Structure”. Chapter 29 in Handbook of Industrial Organization, vol 3, Mark Armstrong and Robert Porter, eds. North-Holland Press.

4) Buerhaus, P, Staiger, D, and Auerbach, D. 2009. The Future of the Nursing Workforce in the United States: Data, Trends, and Implications. Boston, MA: Jones and Bartlett.

5) Brunelle, J.A. and Carlos, J.P. 1990. "Recent Trends in Dental Caries in U.S. Children and the Effect of Water Fluoridation.” J. Dent. Res., 69(Special Issue):723-728.

6) Burt BA and Eklund SA. 1999. Dentistry, dental practice, and the community, 5th ed. Philadelphia, Pennsylvania: WB Saunders.

7) Campbell JR and Lapham B. 2004. "Real Exchange Rate Fluctuations and the Dynamics of Retail Trade Industries on the U.S.-Canada Border.” American Economic Review, 94(4), 1194-1206.

8) Campbell JR and Hubbard TN. 2008. “The Economics of "Radiator Springs”: Industry Dynamics, Sunk Costs, and Spatial Demand Shifts.” Working paper.

9) Centers for Disease Control and Prevention (CDC). 1999. " Achievements in Public Health, 1900-1999: Fluoridation of Drinking Water to Prevent Dental Caries". MMWR 48(41): 933940.

10) Centers for Disease Control and Prevention (CDC). 2008. "Populations receiving optimally fluoridated public drinking water--United States, 1992-2006.” Morb Mortal Wkly Rep. 57(27):737-41

11) Cutler D.M. 1990. “Empirical Evidence of Hospital Delivery Under Prospective Payment.” Mimeo, Massachusetts Institute of Technology.

12) Cutler D.M. 1995. "The Incidence of Adverse Medical Outcomes Under Prospective Payment.” Econometrica 63(1): 29-50.

13) Cutler D.M. and J. Gruber. 1996. "Does Public Insurance Crowd Out Private Insurance?" Quarterly Journal of Economics 111, 391-430.

14) Dafny L. 2005. “How do Hospitals Respond to Price Changes?” American Economic Review 95(5): 1525-1547.

15) Dean HT. 1938. "Endemic fluorosis and its relation to dental caries.” Public Health Rep 53:1443-52.

16) Diesendorf, Mark. 1986. “The mystery of declining tooth decay.” Nature 322(6075): 125129.

17) Dunne T., Roberts M. and Samuelson L. 1989a. "The Growth and Failure of US Manufacturing Plants.” Quarterly Journal of Economics 104: 671-698.

18) Dunne T., Roberts M. and Samuelson L. 1989b. "Plant Turnover and Gross Employment Flows in the US Manufacturing Sector.” Journal of Labor Economics 7: 48-71.

19) Fishman A and Rob R. 2003. "Consumer Inertia, Firm Growth and Industry Dynamics.” Journal of Economic Theory 109(1): 24-38.

20) Gaynor, M., Rebitzer, J.B. and L.J. Taylor. 2004. "Physician Incentives in Health Maintenance Organizations”. The Journal of Political Economy 112(4): 915-931. 
21) Gilman, B.H. 2000. "Hospital Response to DRG Refinements: The Impact of Multiple Reimbursement Incentives on Inpatient Length of Stay.” Health Economics 9(4):277-294.

22) Glied, Sherry and Matthew Neidell. 2009. "The Economic Value of Teeth.” Journal of Human Resources, in press.

23) Griffin SO, Jones K, and Tomar SL. 2001. "An economic evaluation of community water fluoridation.” J Public Health Dent. 61(2):78-86.

24) Gruber J. and K. Simon. 2007. "Crowd-out Ten Years Later: Have Recent Public Insurance Expansions Crowded Out Private Health Insurance?" NBER Working Paper Number 12858.

25) Hopenhayn HA. 1992. "Entry, Exit and Firm Dynamics in Long Run Equilibrium.” Econometrica 60(5): 1127-1150.

26) Iglehart, JA. 2008. "Grassroots Activism and the Pursuit of an Expanded Physician Supply.” New England Journal of Medicine, 358(16): 1741-1749

27) Lakdawalla, D., and T., Philipson (1998), "Industry Performance and The Non-Profit Sector”, Journal of Public Economics, 2006.

28) Newbrun E. 1989. "Effectiveness of water fluoridation.” J Public Health Dent 49:279-89

29) Newhouse, J. (1970). "Towards a Theory Of Non-Profit Institutions: An Economic Model of a Hospital.", American Economic Review, 60(1): 64-74.

30) Yiamouyiannis, John A. 1990. "Water Fluoridation \& Tooth Decay: Results from the 19861987 National Survey of US Schoolchildren." Fluoride: Journal of the International Society for Fluoride Research 23(2):55-67. 
Table 1. Summary statistics

\begin{tabular}{lcccccccc} 
Year & $\begin{array}{c}\text { Dentist } \\
\text { employees } \\
\text { (per 1000) }\end{array}$ & $\begin{array}{c}\text { Dentist } \\
\text { estab. (per } \\
1000)\end{array}$ & $\begin{array}{c}\text { Dentist } \\
\text { payroll } \\
(\$ 1 \mathrm{k})\end{array}$ & $\begin{array}{c}\text { Physician } \\
\text { employees } \\
(\text { per 1000) }\end{array}$ & $\begin{array}{c}\text { Physician } \\
\text { estab. (per } \\
1000)\end{array}$ & $\begin{array}{c}\text { Physician } \\
\text { payroll } \\
(\$ 1 \mathrm{k})\end{array}$ & $\begin{array}{c}\text { \% of } \\
\text { population } \\
\text { CWF }\end{array}$ & $\begin{array}{c}\text { total } \\
\text { population } \\
\text { (millions) }\end{array}$ \\
\hline 1974 & 0.80 & 0.26 & 1.85 & 1.59 & 0.36 & 8.28 & 0.45 & 197 \\
1975 & 0.85 & 0.26 & 2.10 & 1.64 & 0.37 & 9.18 & 0.45 & 199 \\
1976 & 0.90 & 0.27 & 2.34 & 1.69 & 0.37 & 10.09 & 0.45 & 201 \\
1977 & 0.96 & 0.28 & 2.65 & 1.78 & 0.39 & 10.97 & 0.45 & 203 \\
1978 & 1.12 & 0.28 & 2.89 & 1.99 & 0.39 & 11.80 & 0.45 & 206 \\
1979 & 1.20 & 0.28 & 3.10 & 2.12 & 0.40 & 12.64 & 0.46 & 208 \\
1980 & 1.22 & 0.29 & 3.18 & 2.17 & 0.42 & 13.24 & 0.48 & 219 \\
1981 & 1.28 & 0.30 & 3.26 & 2.25 & 0.43 & 14.20 & 0.49 & 221 \\
1982 & 1.37 & 0.31 & 3.63 & 2.34 & 0.46 & 16.29 & 0.50 & 224 \\
1983 & 1.40 & 0.32 & 3.80 & 2.45 & 0.49 & 17.99 & 0.51 & 226 \\
1984 & 1.45 & 0.32 & 3.98 & 2.52 & 0.49 & 18.55 & 0.51 & 228 \\
1985 & 1.49 & 0.32 & 4.16 & 2.56 & 0.48 & 18.81 & 0.51 & 230 \\
1986 & 1.53 & 0.32 & 4.44 & 2.66 & 0.48 & 20.17 & 0.51 & 232 \\
1987 & 1.60 & 0.33 & 5.13 & 2.82 & 0.51 & 23.24 & 0.51 & 234 \\
1988 & 1.63 & 0.33 & 4.95 & 3.15 & 0.51 & 22.32 & 0.52 & 236 \\
1989 & 1.67 & 0.33 & 4.95 & 3.23 & 0.50 & 21.60 & 0.52 & 238 \\
1990 & 1.80 & 0.32 & 4.12 & 3.37 & 0.50 & 20.49 & 0.52 & 242 \\
1991 & 1.80 & 0.32 & 4.22 & 3.45 & 0.50 & 21.22 & 0.52 & 245 \\
1992 & 1.76 & 0.33 & 5.29 & 3.58 & 0.50 & 24.48 & 0.53 & 248 \\
average & 1.36 & 0.30 & 3.69 & 2.49 & 0.45 & 16.61 & 0.49 & 223 \\
\hline
\end{tabular}

Notes: Abbreviations: estab=establishments, payroll = quarterly payroll. 
Table 2. The impact of CWF on dentist supply

\begin{tabular}{lccc}
\multicolumn{2}{c}{$\begin{array}{c}1 \\
\text { establishments }\end{array}$} & $\begin{array}{c}2 \\
\text { employees }\end{array}$ & $\begin{array}{c}3 \\
\text { payroll }\end{array}$ \\
\multicolumn{2}{l}{ A. County fixed effects } & & \\
CWF & 0.026 & 0.124 & 0.00194 \\
& {$[0.009]^{* *}$} & {$[0.065]$} & {$[0.00096]^{*}$} \\
dentist & -1.962 & -4.943 & -0.02338 \\
& {$[0.142]^{* *}$} & {$[0.956]^{* *}$} & {$[0.01013]^{*}$} \\
CWF*dentist $^{*}$ & -0.026 & -0.501 & -0.00391 \\
Observations & {$[0.007]^{* *}$} & {$[0.052]^{* *}$} & {$[0.00051]^{* *}$} \\
R-squared & 99584 & 99786 & 67777 \\
& 0.76 & 0.7 & 0.78
\end{tabular}

B. County fixed effects and county specific linear time trends

\begin{tabular}{lccc}
\hline CWF & 0.016 & 0.145 & 0.00159 \\
& {$[0.007]^{*}$} & {$[0.062]^{*}$} & {$[0.00060]^{* *}$} \\
dentist & -1.985 & -4.810 & -0.01879 \\
& {$[0.142]^{* *}$} & {$[0.948]^{* *}$} & {$[0.01015]$} \\
CWF*dentist & -0.026 & -0.497 & -0.00398 \\
& {$[0.008]^{* *}$} & {$[0.053]^{* *}$} & {$[0.00052]^{* *}$} \\
Observations & 99584 & 99786 & 67777 \\
R-squared & 0.78 & 0.75 & 0.83 \\
\hline Notes: * significant at 5\%; ** significant at 1\%. Standard errors in brackets. Dependent \\
variables are the number of dentists or physicians per 1000 people. All regressions include \\
population distribution, employment distribution, Medicare payments, Medicaid payments, \\
military medical insurance payments, supplemental security income payments, Aid to Families \\
with Dependent Children payments, food stamps payments, unemployment insurance \\
compensation, veterans benefits, federal education and training assistance, current transfer \\
receipts of nonprofit institutions, current transfer receipts of individuals from businesses, average \\
earnings per job, per capita income, and employment to population ratio.
\end{tabular}


Table 3. The impact of CWF on dentist supply dynamics

\begin{tabular}{lccc} 
& $\begin{array}{c}1 \\
\text { employees per } \\
\text { establishment }\end{array}$ & $\begin{array}{c}2 \\
\text { payroll per } \\
\text { establishment }\end{array}$ & $\begin{array}{c}3 \\
\text { payroll per } \\
\text { employee }\end{array}$ \\
\hline CWF & 0.074 & 0.00318 & 0.00028 \\
& {$[0.214]$} & {$[0.00207]$} & {$[0.00010]^{* *}$} \\
dentist & 13.354 & 0.08852 & -0.00285 \\
& {$[3.669]^{* *}$} & {$[0.01856]^{* *}$} & {$[0.00134]^{*}$} \\
CWF*dentist & -1.235 & -0.00742 & -0.00039 \\
& {$[0.191]^{* *}$} & {$[0.00102]^{* *}$} & {$[0.00007]^{* *}$} \\
Observations & 99320 & 67573 & 67571 \\
R-squared & 0.39 & 0.6 & 0.80 \\
\hline
\end{tabular}

Notes: * significant at 5\%; ** significant at $1 \%$. Standard errors in brackets. See notes to Table 2 for included covariates. All regressions include county fixed effects. 
Table 4. The impact of own and neighboring CWF on dentist supply

\begin{tabular}{lccc} 
& 1 & 2 & 3 \\
& establishments & employees & payroll \\
\hline A. All neighbors & & & \\
dent*CWF own & -0.02659 & -0.57853 & -0.00442 \\
& {$[0.01130]^{*}$} & {$[0.07626]^{* *}$} & {$[0.00081]^{* *}$} \\
dent*CWF neighbor & 0.02022 & 0.18931 & 0.00145 \\
& {$[0.00508]^{* *}$} & {$[0.03478]^{* *}$} & {$[0.00035]^{* *}$} \\
Observations & 675546 & 676832 & 473367 \\
R-squared & 0.79 & 0.73 & 0.79 \\
& & & \\
B. Closest neighbor & & -0.57161 & -0.00467 \\
dent*CWF own & -0.03164 & {$[0.05929]^{* *}$} & {$[0.00059]^{* *}$} \\
& {$[0.00820]^{* *}$} & 0.2147 & 0.00196 \\
dent*CWF neighbor & 0.03755 & {$[0.04690]^{* *}$} & {$[0.00051]^{* *}$} \\
& {$[0.00695]^{* *}$} & 91686 & 63002 \\
Observations & 91503 & 0.70 & 0.78 \\
R-squared & 0.77 & 0.5619
\end{tabular}

Notes: * significant at 5\%; ** significant at $1 \%$. Standard errors in brackets. See notes to Table 2 for included covariates. All regressions include county fixed effects. 
Table 5. Impact of CWF on dentist composition

\begin{tabular}{|c|c|c|c|c|}
\hline & $\begin{array}{c}1 \\
\mathrm{GP} /(\mathrm{GP}+\text { specialist })\end{array}$ & $\begin{array}{c}2 \\
\mathrm{FT} /(\mathrm{FT}+\mathrm{PT})\end{array}$ & $\begin{array}{c}3 \\
\text { Age }<44 /(\text { Age }<44+ \\
\text { Age }>44)\end{array}$ & $\begin{array}{c}4 \\
\text { Private/(Private+ } \\
\text { Public) }\end{array}$ \\
\hline \multirow[t]{2}{*}{ CWF } & -0.031 & -0.015 & -0.014 & 0.001 \\
\hline & {$[0.006]^{* *}$} & {$[0.014]$} & {$[0.014]$} & {$[0.007]$} \\
\hline Mean GP/FT/Age<44/Private 1981 & 0.345 & 0.309 & 0.206 & 0.349 \\
\hline Mean spec./PT/Age>44/Public 1981 & 0.023 & 0.042 & 0.165 & 0.017 \\
\hline Mean GP/FT/Age<44/Private 1987 & 0.345 & 0.303 & 0.211 & 0.368 \\
\hline Mean spec./PT/Age>44/Public 1987 & 0.032 & 0.065 & 0.169 & 0.007 \\
\hline Mean dependent variable & 0.94 & 0.86 & 0.57 & 0.97 \\
\hline Observations & 5253 & 5248 & 5253 & 5253 \\
\hline R-squared & 0.92 & 0.73 & 0.83 & 0.77 \\
\hline
\end{tabular}

Notes: * significant at 5\%; ** significant at 1\%. Standard errors in brackets. GP = general practitioner or pediatric dentist, FT $=$ fulltime, $\mathrm{PT}=$ part-time. See notes to Table 2 for included covariates. All regressions include county fixed effects. All regressions are weighted by the denominator of the dependent variable. 
Table 6. Association between CWF and dental cleanings

\begin{tabular}{|c|c|c|c|c|c|c|}
\hline & 1 & 2 & 3 & 4 & 5 & 6 \\
\hline \multirow[t]{2}{*}{ CWF } & 0.009 & 0.011 & 0.010 & -0.031 & -0.039 & -0.034 \\
\hline & {$[0.008]$} & {$[0.007]$} & {$[0.007]$} & {$[0.024]$} & {$[0.023]$} & {$[0.022]$} \\
\hline Observations & 93770 & 93770 & 93770 & 92703 & 92703 & 92703 \\
\hline dependent variable & $\begin{array}{c}\text { cleaning in past } \\
\text { year }\end{array}$ & $\begin{array}{c}\text { cleaning in past } \\
\text { year }\end{array}$ & $\begin{array}{c}\text { cleaning in past } \\
\text { year }\end{array}$ & $\begin{array}{l}\text { years since } \\
\text { cleaned }\end{array}$ & $\begin{array}{c}\text { years since } \\
\text { cleaned }\end{array}$ & $\begin{array}{c}\text { years since } \\
\text { cleaned }\end{array}$ \\
\hline regression model & linear probability & linear probability & linear probability & $\begin{array}{l}\text { interval } \\
\text { regression }\end{array}$ & $\begin{array}{l}\text { interval } \\
\text { regression }\end{array}$ & $\begin{array}{l}\text { interval } \\
\text { regression }\end{array}$ \\
\hline county chars. & $\mathrm{y}$ & $\mathrm{y}$ & $\mathrm{y}$ & $\mathrm{y}$ & $\mathrm{y}$ & $\mathrm{y}$ \\
\hline basic demographics & $\mathrm{n}$ & $\mathrm{y}$ & $\mathrm{y}$ & $n$ & $\mathrm{y}$ & $\mathrm{y}$ \\
\hline health behaviors & $\mathrm{n}$ & $\mathrm{n}$ & $\mathrm{y}$ & $\mathrm{n}$ & $\mathrm{n}$ & $\mathrm{y}$ \\
\hline
\end{tabular}

Notes: * significant at 5\%; ** significant at 1\%. Standard errors clustered on county in brackets. All regressions include 10 -year age category dummies and state dummies. 'County chars' includes population density, median age, percent race/ethnicity breakdown, persons per household, death rate, infant mortality rate, percent high school graduates, percents college grades, median household income, percent poverty, unemployment rate, and social security collection rate. 'Basic demographics' include gender, race,

education, marital status, number of children, employment status, and health insurance status. 'Health behaviors' include diabetes, number of bad mental health days, body mass index, blood pressure checked in past year, smoking status, and frequency of routine check-ups. 